\title{
Prediction of Flow Regimes and Thermal Hydraulic Parameters in Two-Phase Natural Circulation by RELAP5 and TRACE Codes
}

\author{
Viet-Anh Phung and Pavel Kudinov \\ Nuclear Power Safety Division, KTH Royal Institute of Technology, 10691 Stockholm, Sweden \\ Correspondence should be addressed to Viet-Anh Phung; vaphung@kth.se
}

Received 28 August 2015; Revised 22 October 2015; Accepted 25 October 2015

Academic Editor: Alejandro Clausse

Copyright ( 2015 V.-A. Phung and P. Kudinov. This is an open access article distributed under the Creative Commons Attribution License, which permits unrestricted use, distribution, and reproduction in any medium, provided the original work is properly cited.

\begin{abstract}
In earlier study we have demonstrated that RELAP5 can predict flow instability parameters (flow rate, oscillation period, temperature, and pressure) in single channel tests in CIRCUS-IV facility. The main goals of this work are to (i) validate RELAP5 and TRACE capabilities in prediction of two-phase flow instability and flow regimes and (ii) assess the effect of improvement in flow regime identification on code predictions. Most of the results of RELAP5 and TRACE calculation are in reasonable agreement with experimental data from CIRCUS-IV. However, both codes misidentified instantaneous flow regimes which were observed in the test with high speed camera. One of the reasons for the incorrect identification of the flow regimes is the small tube flow regime transition model in RELAP5 and the combined bubbly-slug flow regime in TRACE. We found that calculation results are sensitive to flow regime boundaries of RELAP5 which were modified in order to match the experimental data on flow regimes. Although the flow regime became closer to the experimental one, other predicted thermal hydraulic parameters showed larger discrepancy with the experimental data than with the base case calculations where flow regimes were misidentified.
\end{abstract}

\section{Introduction}

The rates of exchange of mass, energy, and momentum between vapor and liquid phases are sensitive to topology of the vapor and liquid or flow regime. Flow regimes have been extensively studied experimentally and transition between different regimes has been introduced as flow regime maps. The flow regimes influence simulation results through the closures, which are specific for each flow regime. However, most of the previous works on flow regimes were carried out for fully developed steady state flow conditions $[1,2]$.

System thermal hydraulic (STH) codes RELAP5 $[3,4]$ and TRACE [5] are widely used in nuclear reactor design and safety analysis. Both codes use two-phase flow regime maps and flow specific correlations that are validated against steady state experiments. While in the codes flow regime can change instantaneously, in reality flow regimes require time to develop [6]. Instantaneous flow regimes in unsteady conditions can be different from those observed in steady state [7, 8]. There is a concern that misidentification of the transient flow regimes can significantly affect prediction results of thermal hydraulics during two-phase flow instability.

In earlier work [9], RELAP5 was validated against twophase natural circulation flow instability data from CIRCUSIV single channel tests. We have developed and applied a procedure for input calibration and STH code validation employing data with multiple measured parameters in different test regimes. The study showed that in general RELAP5 can predict thermal hydraulic parameters of two-phase flow instability at atmospheric pressure. Discrepancies between calculation and experiment were smaller for low frequency oscillations than for high frequency oscillations. It was suggested that one of the possible reasons for the observed discrepancies is misidentification of two-phase flow regime by RELAP5. If that is the case, it is important to understand why the codes could not identify correctly the flow regimes; why the calculation results were generally in good agreement with the experimental data without correct flow regime identification; how the steady state flow regime map affects prediction of two-phase natural circulation flow instability; 


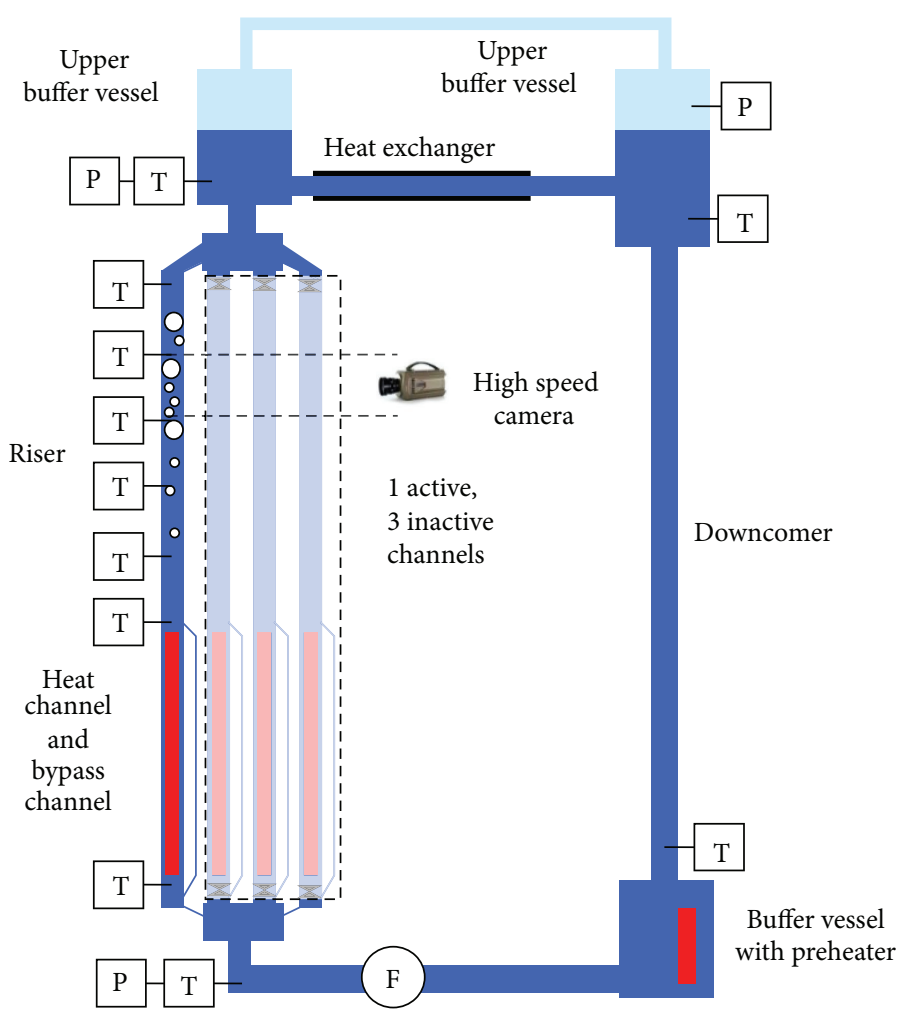

(a)

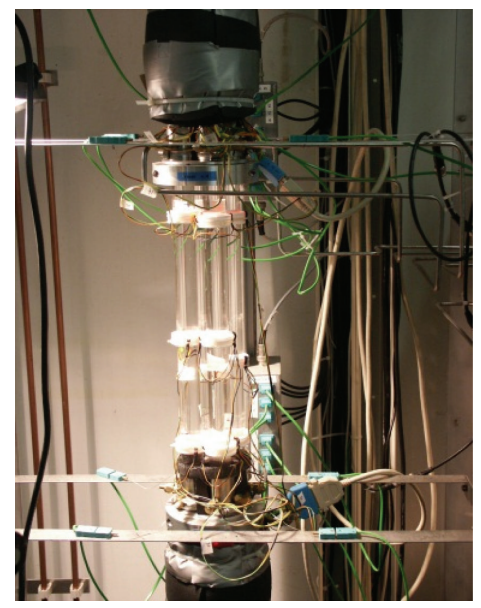

(b)

FIgURE 1: CIRCUS-IV test facility (a) and uncovered riser section for flow observation (b).

and how sensitive to the flow regimes the prediction of instability is.

The main goals of this work are (i) to validate RELAP5 and TRACE capabilities in prediction of the two-phase flow instability including identification of instantaneous flow regimes and (ii) to assess the effect of improvement in flow regime identification on code predictions.

In order to achieve the goals, we, first, carried out comparison of calculated and experimental data including flow regimes (recorded with a high speed camera), and, second, assessed the sensitivity of flow characteristics to modification of the flow regime map in RELAP5. Flow regime map modification analysis was not done for TRACE due to lack of the source code.

In Section 2 of this paper, we provide description of the CIRCUS-IV single channel experimental setup and a set of steady state and instability tests used for input calibration and code validation. Section 3 describes RELAP5 and TRACE models of the facility and modifications to the flow regime transition boundaries in RELAP5. Capabilities of the codes in prediction of instability and identification of the flow regimes and effect of flow regime identification on prediction outcome are discussed in Section 4.

\section{Experiment}

The CIRCUS-IV [10] is a natural circulation test loop facility at the Delft University of Technology that was designed to investigate characteristics of the two-phase flow instability with primary application to natural circulation boiling water reactors during the start-up phase.

The scheme of the facility including instrumentation is shown in Figure 1(a). The loop consists of a test section with four parallel channels, a heat exchanger, a downcomer, two upper buffer vessels with steam domes, and a lower buffer vessel with a preheater. Each parallel channel consists of a heated section $(1.95 \mathrm{~m})$ with a heated rod inside, a bypass, and a riser section $(3 \mathrm{~m})$. Temperature of water at the inlet of the test section is controlled by the preheater.

The main instrumentation includes the following:

(1) volumetric magnetic flow-meter located at the inlet of the test section;

(2) thermocouples at the inlet of the test section (1x), at the inlet of the heated channel (1x), along the riser $(6 \mathrm{x})$, and in the buffer vessels (3x);

(3) pressure sensors at the inlet of the test section, the riser outlet, and the steam dome;

(4) a high-speed camera (200 frames per second) located in front of the uncovered riser section $1.8 \mathrm{~m}$ above the top of heated section (Figure 1(b)). Snapshots of four instantaneous flow regimes identified during the experiments are shown in Figure 2.

Experimental errors were $\pm 1^{\circ} \mathrm{C}$ for temperature, \pm 30 mbar for pressure, and $\pm 0.0002 \mathrm{~L} / \mathrm{s}$ for flow rate measurements. 


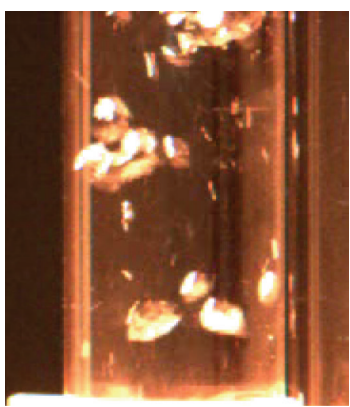

Bubbly

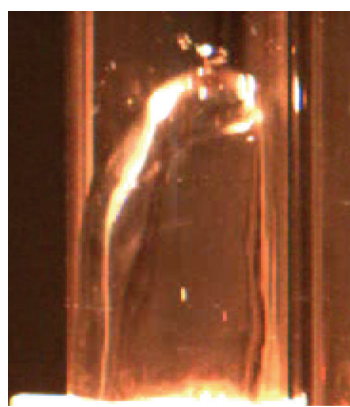

Slug

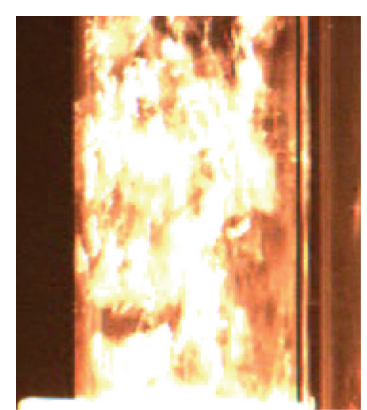

Churn

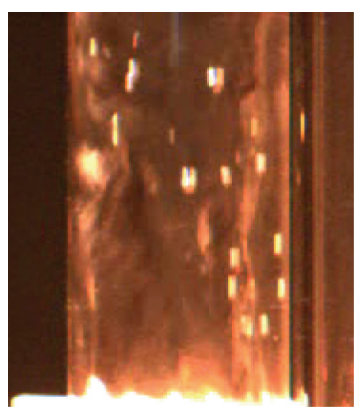

Annular

FIGURE 2: Experimental flow regime identification.

For the code validation purpose, we performed the experiments with a single test section channel opened to eliminate possible mutual effects of flows in parallel channels. Since dynamic of the flow instability is sensitive to the variation of steam dome pressure, the steam domes were opened to the atmosphere to maintain constant pressure. All bypass channels were closed.

Carried out experiments are presented in Table 1. Single phase steady state natural circulation was established in test S-1 and two-phase natural circulation flow with intermittent oscillations was observed in tests I-1 and I-2. These oscillating flows are categorized as flashing instability [11, 12]. Figure 3 shows the inlet flow rate in the tests: amplitude and frequency of flow oscillations increased with the rise in inlet water temperature. The transition from single phase to two-phase flow occurred at inlet water temperature around $90-92^{\circ} \mathrm{C}$.

\section{RELAP5 and Trace Modelling}

3.1. Input Models. RELAP5 Mod 3.3gl and TRACE version 5.0 pack 2 were used in this work. Nodalization of the facility in the codes is shown in Figure 4. Both input models include the heated channel with a heated rod, the riser, the heat exchanger, the downcomer, two upper buffer vessels with steam domes, the lower buffer vessel with preheater, and heat structures for the heated channels, the riser, the heat exchanger, and the downcomer.

The following thermal hydraulic parameters were analyzed in the study: inlet flow rate, riser water temperatures, inlet pressure, riser flow regime and void fraction, and riser vapor generation rate. No experimental data was available for the void fraction and vapor generation rate in the riser; therefore, RELAP5 and TRACE results for these parameters were compared to each other.

Details of the input calibration and code validation are provided in [9].

3.2. Flow Regime Boundaries in RELAP5. The boundary between bubbly and slug regime in steady state flow conditions is observed at the void fraction approximately 0.25 [13]. Churn and annular flow regime are observed in the ranges
TABLE 1: Test conditions and regimes.

\begin{tabular}{lcccc}
\hline Test & $\begin{array}{c}\text { System } \\
\text { pressure } \\
(\text { bar })\end{array}$ & $\begin{array}{c}\text { Heater power } \\
(\mathrm{kW})\end{array}$ & $\begin{array}{c}\text { Inlet water } \\
\text { temperature } \\
\left({ }^{\circ} \mathrm{C}\right)\end{array}$ & Test regime \\
\hline S-1 & 1 & 2.5 & 89.7 & $\begin{array}{c}\text { Single phase } \\
\text { steady state } \\
\text { Two-phase } \\
\text { I-1 }\end{array}$ \\
& 1 & 2.5 & 92.8 & $\begin{array}{c}\text { instability } \\
\text { Two-phase } \\
\text { instability }\end{array}$ \\
I-2 & 1 & 2.5 & 99.8 & \\
\hline
\end{tabular}

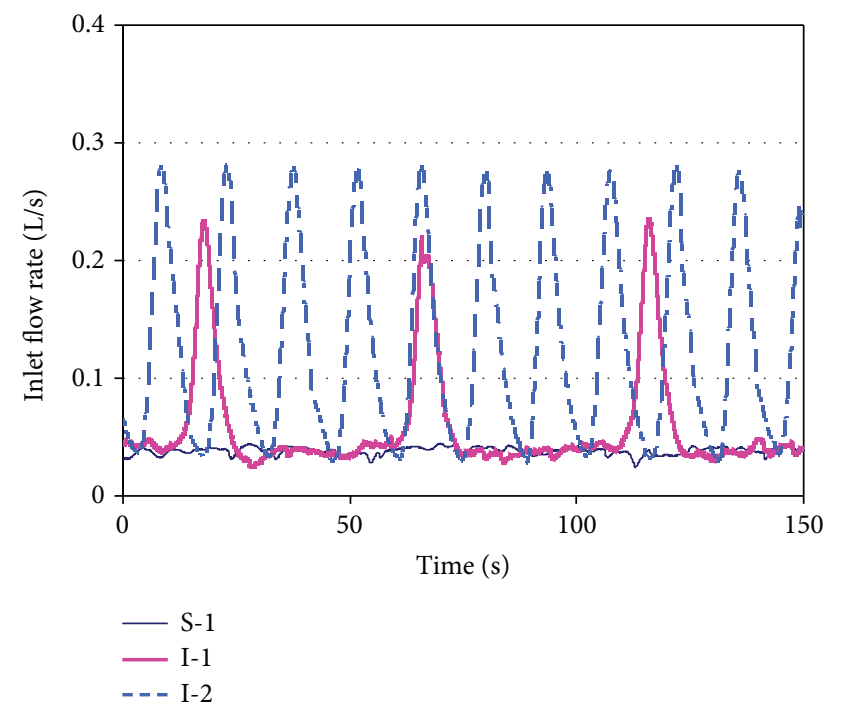

FIGURE 3: Inlet flow rate in the CIRCUS-IV single channel experiments.

of void fraction $0.5-0.7$ and $0.7-0.9$, respectively [14]. Actual boundaries between the regimes are also dependent on the mass flow rate, effective diameter of the flow path, and the flow direction.

In RELAP5, flow regime transition boundaries are defined mainly in terms of void fraction [4]. Bubbly-to-slug 


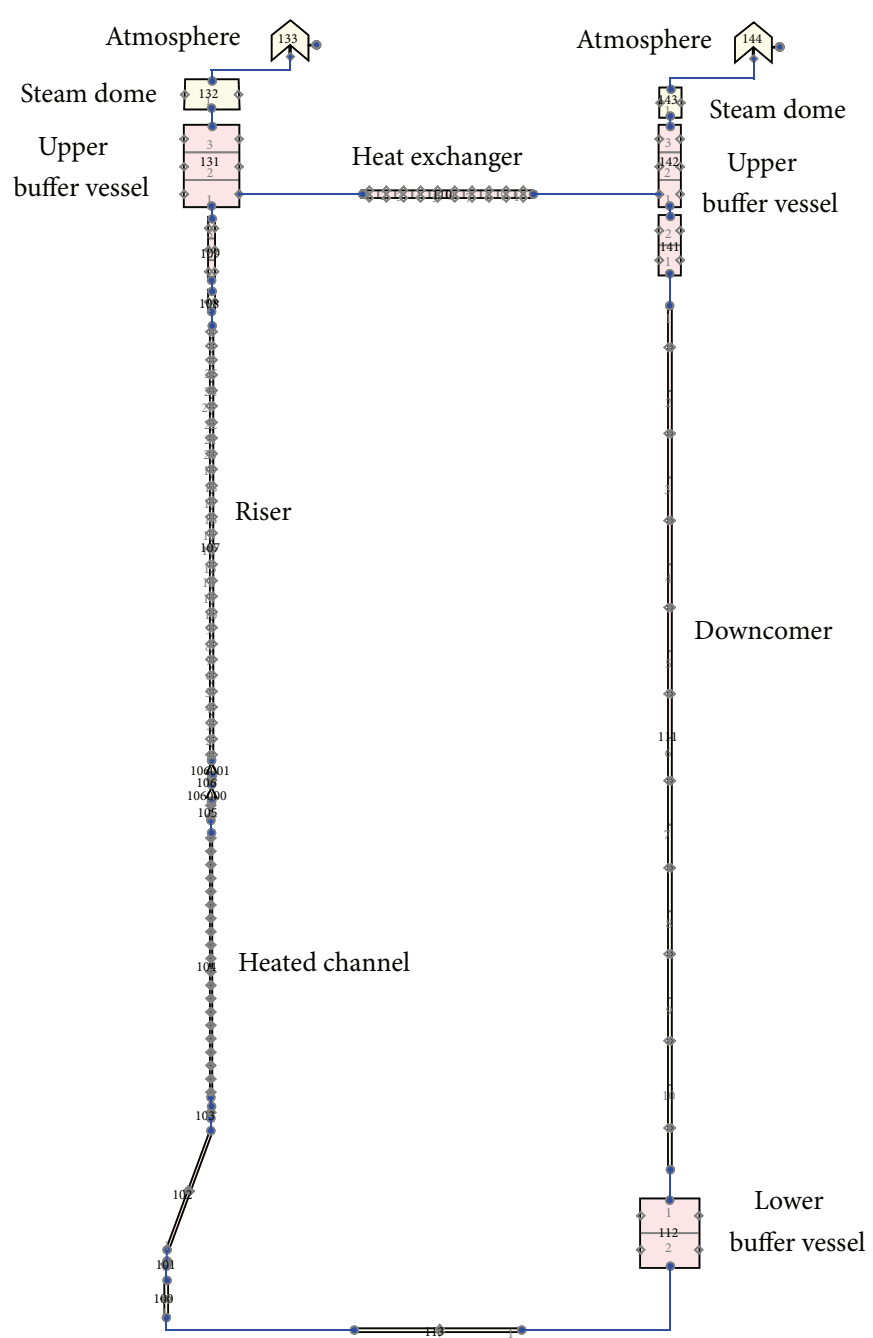

FIGURE 4: RELAP5 and TRACE nodalization of the CIRCUS-IV single channel tests.

flow regime transition boundaries $\left(\alpha_{\mathrm{BS}}\right)$ for vertical flow are as follows:

$$
\begin{aligned}
& \alpha_{\mathrm{BS}}=\alpha_{\mathrm{BS}}^{*} \quad \text { for } G_{m} \leq 2000 \mathrm{~kg} / \mathrm{m}^{2} \mathrm{~s}, \\
& \alpha_{\mathrm{BS}}=\alpha_{\mathrm{BS}}^{*}+\frac{\left(0.5-\alpha_{\mathrm{BS}}^{*}\right)}{1000}\left(G_{m}-2000\right) \\
& \text { for } 2000<G_{m}<3000 \mathrm{~kg} / \mathrm{m}^{2} \mathrm{~s}, \\
& \alpha_{\mathrm{BS}}=0.5 \quad \text { for } G_{m} \geq 3000 \mathrm{~kg} / \mathrm{m}^{2} \mathrm{~s}, \\
& \alpha_{\mathrm{BS}}^{*}=\max \left\{0.25 \min \left[1,\left(0.045 D^{*}\right)^{8}\right], 10^{-3}\right\}, \\
& D^{*}=D\left[\frac{g\left(\rho_{f}-\rho_{g}\right)}{\sigma}\right]^{1 / 2},
\end{aligned}
$$

where $G_{m}$ is mass flux, $D$ is diameter of the pipe, $\sigma$ is surface tension, and $\rho_{f}$ and $\rho_{g}$ are density of liquid and gas, respectively.
Figure 5 shows the effect of pipe diameter on the bubblyto-slug transition boundary of the code at $G_{m} \leq 2000 \mathrm{~kg} / \mathrm{m}^{2} \mathrm{~s}$, that is, in conditions similar to I-1 and I-2 tests.

Slug-to-annular transition boundary $\left(\alpha_{\mathrm{SA}}\right)$ is defined in RELAP as

$$
\alpha_{\mathrm{SA}}=\max \left\{0.8, \min \left[\alpha_{\text {crit }}, \alpha_{\text {film }}, 0.9\right]\right\},
$$

where $v_{g}$ is gas velocity and

$$
\begin{aligned}
& v_{\text {critl }}=5.66 *\left(\frac{\sigma\left(\rho_{f}-\rho_{g}\right)}{\rho_{g}}\right)^{1 / 4}, \\
& v_{\text {film }}=3.13 *\left(\frac{D\left(\rho_{f}-\rho_{g}\right)}{\rho_{g}}\right)^{1 / 2}, \\
& \alpha_{\text {crit }}=\frac{v_{\text {crit } l}}{\max \left\{\left|v_{g}\right|, v_{\text {crit } l}\right\}}, \\
& \alpha_{\text {film }}=\frac{v_{\text {film }}}{\max \left\{\left|v_{g}\right|, v_{\text {film }}\right\}}+0.75 .
\end{aligned}
$$




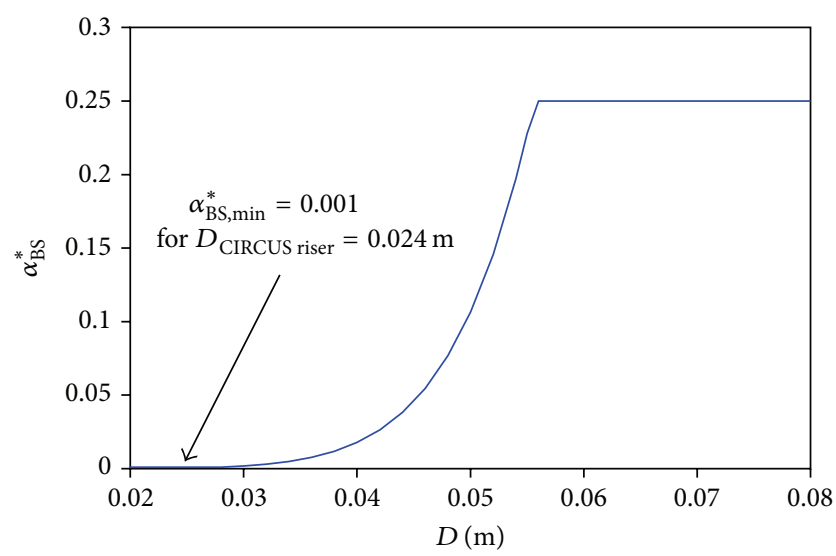

FIGURE 5: RELAP5 bubbly-to-slug transition boundary depending on the pipe diameter at $G_{m} \leq 2000 \mathrm{~kg} / \mathrm{m}^{2}$ s.

TABLE 2: Calibrated values of uncertain input parameters, test S-1.

\begin{tabular}{lccc}
\hline Input parameter & TRACE & RELAP5 & Experiment \\
\hline Channel inlet temperature $\left({ }^{\circ} \mathrm{C}\right)$ & 89.8 & 89.8 & 89.0 \\
Heated channel heat loss $(\mathrm{W})$ & 350 & 350 & N/A \\
Riser heat loss $(\mathrm{W})$ & 200 & 200 & N/A \\
Upper riser tube heat loss $(\mathrm{W})$ & 200 & 200 & N/A \\
Inlet loss coefficient & 28 & 28 & N/A \\
\hline
\end{tabular}

In this work we study the sensitivity of characteristics of twophase natural circulation flow instability to modification of the flow regime map in RELAP5. The modifications were done by changing the bubbly-to-slug $\left(\alpha_{\mathrm{BS}}^{*}\right)$ and slug-toannular $\left(\alpha_{\mathrm{SA}}\right)$ transition boundaries in the source code.

\section{Results and Discussion}

\subsection{RELAP5 and Trace Validation}

4.1.1. Single Phase Steady State Calculations with Calibrated Input. Calibrated values of codes' uncertain input parameters are listed in Table 2 for test S-1. The values of predicted output parameters and the experimental data are summarized in Table 3. In this case, the discrepancy between RELAP5 and TRACE predictions was marginal. In comparison to the experiment, the predicted values are within the ranges of $\pm 2 \%$ for flow rate, $\pm 0.5 \%$ for water temperature, and $\pm 0.1 \%$ for absolute pressure, which can be considered acceptable calculation errors for single phase steady state qualification [15].

4.1.2. Two-Phase Instability Calculations with Calibrated Input. The values of the input parameters which are not measured directly in the experiment (such as heat losses and loss coefficients) were calibrated using data from single phase steady state test S-1 (Table 4). For the instability tests I-2 and $\mathrm{I}-1$ the inlet water temperature was set to $0.8^{\circ} \mathrm{C}$ higher than the raw experimental data. This correction was within the measurement uncertainty.
TABLE 3: Output parameters, test S-1.

\begin{tabular}{lccc}
\hline Output parameter & TRACE & RELAP5 & Experiment \\
\hline Inlet flow rate $(\mathrm{L} / \mathrm{s})$ & 0.0397 & 0.0405 & 0.0402 \\
Riser inlet temperature $\left({ }^{\circ} \mathrm{C}\right)$ & 103.7 & 103.5 & 103.8 \\
Riser outlet temperature $\left({ }^{\circ} \mathrm{C}\right)$ & 102.1 & 102.0 & 102.5 \\
Inlet pressure (bar) & 1.651 & 1.652 & 1.650 \\
\hline
\end{tabular}

TABLE 4: Calibrated values of uncertain input parameters, tests I-2 and I-1.

\begin{tabular}{lccc}
\hline Input parameter & $\begin{array}{c}\text { TRACE } \\
\text { I-2/I-1 }\end{array}$ & $\begin{array}{c}\text { RELAP5 } \\
\text { I-2/I-1 }\end{array}$ & $\begin{array}{c}\text { Experiment } \\
\text { I-2/I-1 }\end{array}$ \\
\hline $\begin{array}{l}\text { Channel inlet } \\
\text { temperature }\left({ }^{\circ} \mathrm{C}\right)\end{array}$ & $100.6 / 93.6$ & $100.6 / 93.6$ & $99.8 / 92.8$ \\
$\begin{array}{l}\text { Heated channel } \\
\text { heat loss (W) }\end{array}$ & 350 & 350 & N/A \\
$\begin{array}{l}\text { Riser heat loss (W) } \\
\text { Upper riser tube } \\
\text { heat loss (W) }\end{array}$ & 200 & 200 & N/A \\
$\begin{array}{l}\text { Inlet loss } \\
\text { coefficient }\end{array}$ & 200 & 200 & N/A \\
\hline
\end{tabular}

Results of tests I- 2 and I-1 simulations are summarized in Table 5. In general, the amplitude of instability was better predicted by RELAP5. The oscillation period was better captured by TRACE. The error in prediction of the oscillation period was up to $+27 \%$ for RELAP5 while it did not exceed $-7 \%$ for TRACE. Both codes significantly overestimated the maximum inlet flow rate: up to $17 \%$ for RELAP5 and up to $59 \%$ for TRACE. The average inlet flow rate was predicted better by RELAP 5 with error from 0 to $+7 \%$, while the value was underestimated by TRACE with error from $-10 \%$ to $-17 \%$. The minimum inlet flow rate was predicted with error from 0 to $+32 \%$, which is in the range of experimental error (the experimental value was small and varied in the range of $\pm 30 \%)$. Importantly, both codes could not identify correctly the instantaneous flow regimes including the types of flow regime and timing of the regime transition.

(i) Test I-2 $\left(T_{\text {in }}=100^{\circ} \mathrm{C}\right)$. For test I-2, RELAP5 provided more accurate prediction of the inlet flow rate and the oscillation period than TRACE did. Both codes provided higher but narrower peaks of the flow rate in comparison to the experiment (Figure 6). While the flashing duration was significantly shorter in calculations, the overall oscillation period predicted by the codes was only slightly underestimated: $0.5 \%$ for RELAP5 and $6.3 \%$ for TRACE (Table 5). The maximum inlet flow rate predicted by TRACE was overestimated by $28 \%$, while the average inlet flow rate was underestimated by $16 \%$.

TRACE uses bubbly-slug as a combined flow regime. Both codes consider single phase as a part of bubbly flow regime. There are significant discrepancies between experimental instantaneous flow regimes and flow regimes identified by the codes (Figure 7). Bubbly, slug and periodically changing churn and annular flow regimes were observed in experiment during each cycle of flashing. RELAP5 predicted 
TABLE 5: Calculated inlet flow rate, oscillation period, and errors normalized to the experiment, tests I-2 and I-1.

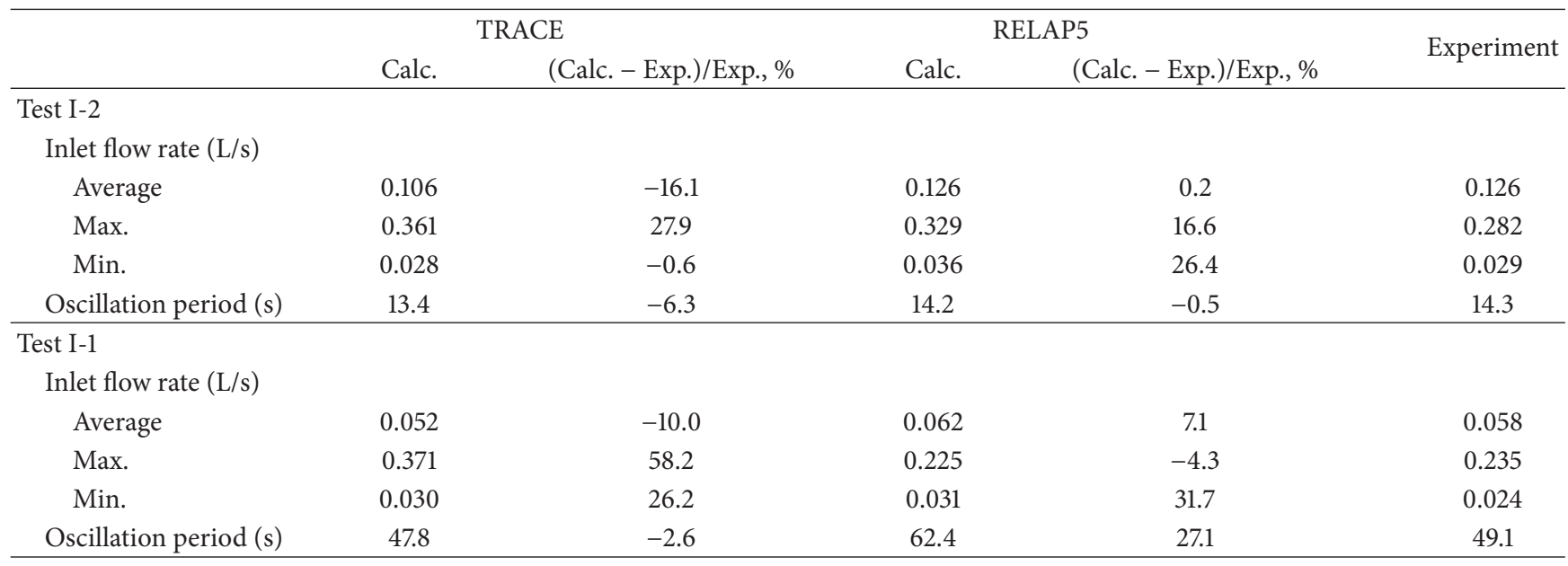

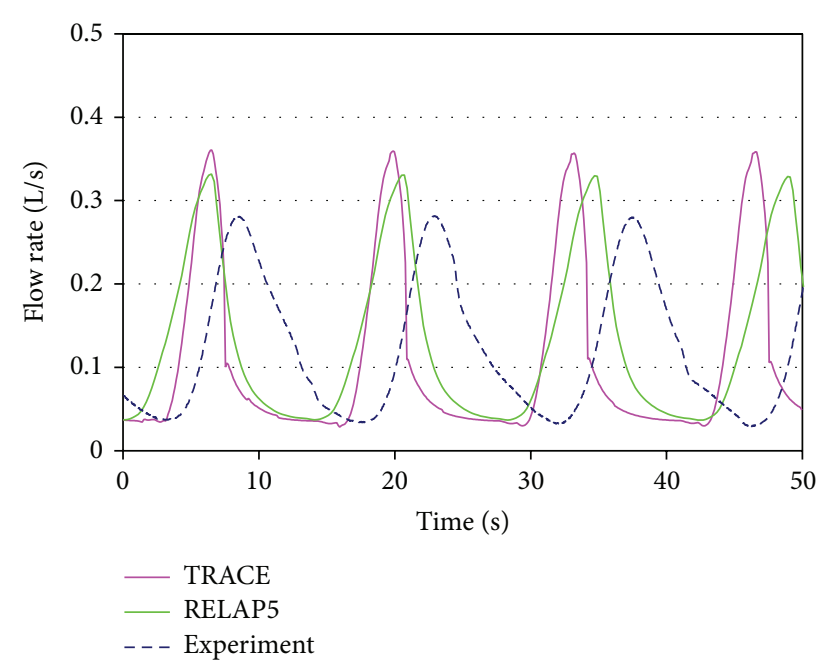

Figure 6: Test I-2: inlet flow rate.

only bubbly and slug flow regimes. No changes in the flow regime were predicted by TRACE during the transient. The timing of transition between the regimes was mispredicted by RELAP5.

It is remarkable that void fraction predicted by both codes qualitatively follows transient behavior of experimentally observed flow regimes (see Figure 7). RELAP5 predicted slightly lower void fraction in the riser (Figure 7) and consequently lower pressure drop at the inlet of the test section upon the flashing (Figure 8) in comparison to TRACE.

It is instructive to note that there is a delay of $\sim 2 \mathrm{~s}$ in experiment between the time moments when pressure reaches its minimum and flow rate reaches its maximum. Such shift is observed neither in RELAP5 nor in TRACE calculations. The maximum flow rate is predicted at the same time moment as the minimum of the pressure by both codes. This can be considered as an evidence for the need of code model improvement. RELAP5 predicts practically the same period of oscillations as in the experiment $(\sim 14.2 \mathrm{sec})$. In Figure 6 the time shift between the maximum flow rate
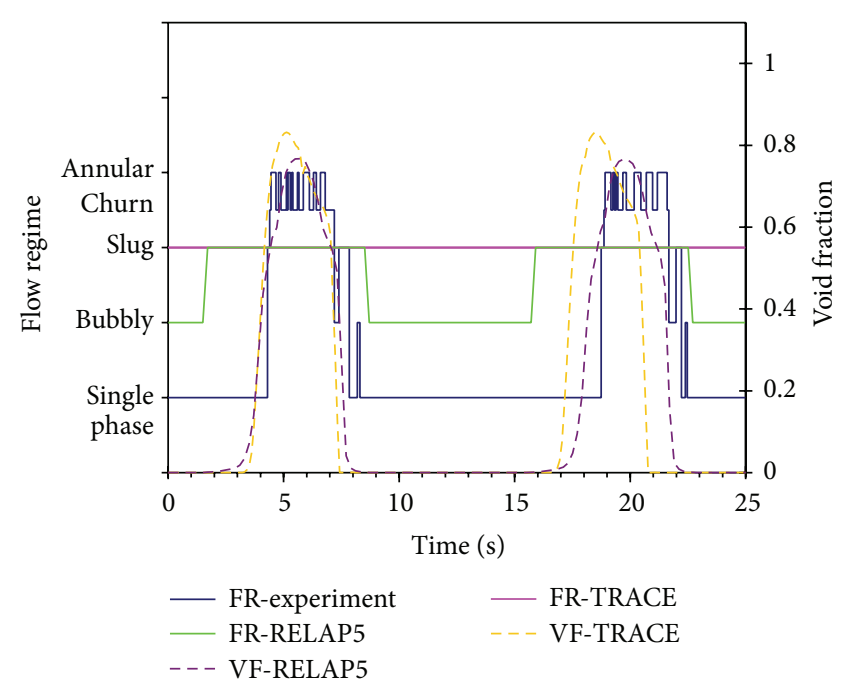

FIGURE 7: Test I-2: riser flow regime (FR) and void fraction (VF) in the section for visual observation.

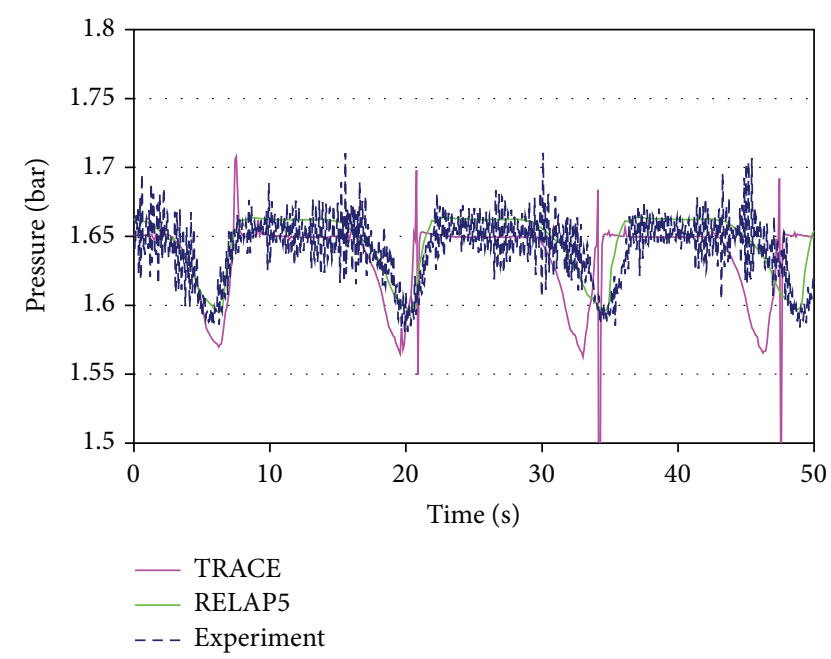

FIGURE 8: Test I-2: inlet pressure. 


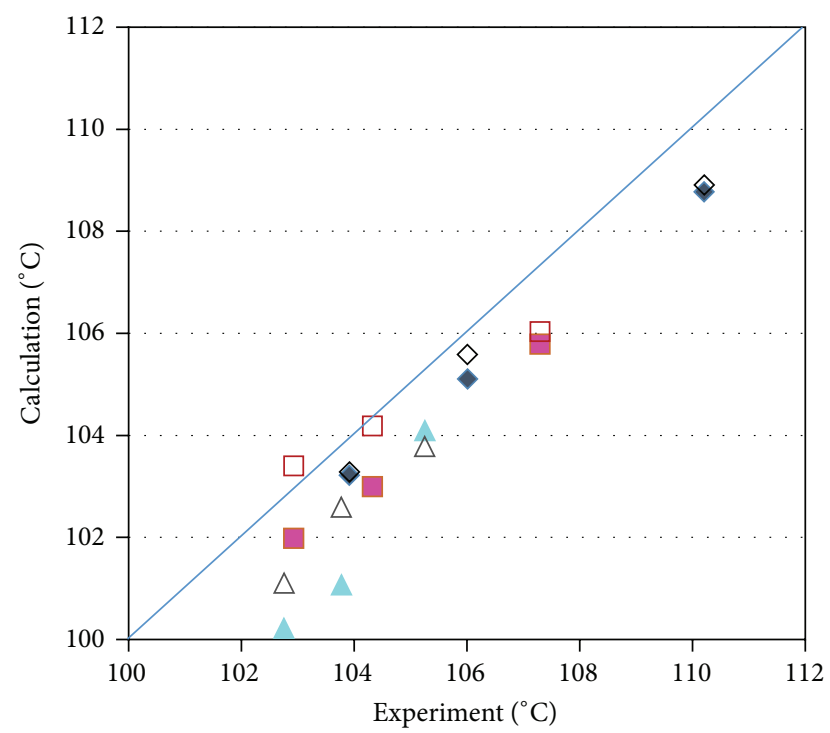

$$
\begin{array}{ll}
- \text { TRACE-riser inlet } & \diamond \text { RELAP5-riser inlet } \\
\text { TRACE-riser middle } & \square \text { RELAP5-riser middle } \\
\triangle \text { TRACE-riser exit } & \triangle \text { RELAP5-riser exit }
\end{array}
$$

Figure 9: Test I-2: water temperature in the riser. Maximum, average, and minimum values are provided for each parameter.

in RELAP5 and that in experiment is $\sim 2 \mathrm{sec}$. Therefore, it appears that in Figure 8 pressure predicted by RELAP5 is in phase with the experiment. Period predicted by TRACE is smaller $(\sim 13.4 \mathrm{sec})$ than that in experiment. Therefore, it appears that pressure predicted by TRACE is out of phase with experiment (Figure 8).

Figure 9 compares the calculated and experimental water temperature in the riser inlet, middle, and outlet. Each temperature parameter is represented by maximum, average, and minimum values. In general, the calculated water temperatures in the riser were underestimated. RELAP5 gave better prediction than TRACE. The underestimation was in the range of $1^{\circ} \mathrm{C}$ in most of the cases, which is within the measurement error range. For TRACE prediction, the underestimation was up to $3^{\circ} \mathrm{C}$ for the riser exit water temperature (minimum and average values).

An instability period can be divided into two parts: incubation period and flashing period. During the incubation period, the flow rate is low, while water temperature in the test section increases with time. The maximum temperature of the water in the riser is limited by the saturation point. This explains almost similar maximum temperatures of water in the riser predicted by RELAP5 and TRACE. During the flashing, the flowrate rapidly increases and then goes back to the preflashing low level, at the same time the riser water temperature drops from the maximum to its minimum value. More energetic flashing results in faster transfer of cold water from lower parts into the riser. Therefore, lower minimum and average temperatures of water in the riser were obtained in TRACE calculations with more energetic flashing.

We further compared the predicted vaporization/condensation rates along the riser. More vapor was generated at the top and less as inlet of the riser in RELAP5 calculations. TRACE simulations predicted an opposite tendency and showed strong oscillatory evaporation and condensation (Figure 10).

(ii) Test I-1 $\left(T_{\text {in }}=93^{\circ} \mathrm{C}\right)$. For test I-1, RELAP5 provides reasonable prediction of the maximum flow rate but overestimates the oscillation period by $27 \%$, while TRACE predicts the oscillation period but overestimates the maximum inlet flow rate by $58 \%$ (Table 5 ). The flashing time was significantly longer in RELAP5 predictions than in the experiment, while TRACE predicted shorter but stronger flashing (Figure 11).

Similar to test I-2, both codes mispredicted the flow regimes (Figure 12). Bubbly, slug, churn, and annular flow regimes were observed in the experiments. Only bubbly and slug flow regimes were predicted by RELAP5 and TRACE. Much higher void fraction (up to 0.8 ) was obtained in TRACE in comparison to RELAP5 (up to 0.35); see Figure 12. Void fraction ranges predicted by TRACE are in a qualitatively better agreement with experimentally observed flow regimes than those predicted by RELAP5.

(iii) Discussion of the Flow Regime Misprediction. One of the reasons for the incorrect identification of the bubbly and slug flow regimes is the small pipe flow regime transition model in RELAP5. The diameter of a CIRCUS-IV riser is $0.024 \mathrm{~m}$; thus the code identified the bubbly-to-slug flow regime transition boundary $\alpha_{\mathrm{BS}}$ at 0.001 in the test condition (instead of 0.25 for pipes with diameter larger than $0.055 \mathrm{~m}$ ); see Figure 5. This boundary resulted in the predicted moment of transition from bubbly to slug flow which occurred much earlier $(\sim 3-5 s)$, while the reverse transition from slug to bubbly flow happened later ( 1-2 s) than those events in the experiments (Figures 7 and 12). In addition to the CIRCUSIV single channel tests, other experiments such as Chen et al.'s [16] showed that bubbly flow regime does exist in small diameter (down to few millimeters scale) pipes. Therefore, the preclusion of bubbly flow in small diameter pipe in the code does not correspond to the experimental observations of the actual flow regimes.

Absence of annular flow regime in code prediction can be due to the slug-to-annular flow regime transition boundary $\alpha_{\mathrm{SA}}$, which is defined in RELAP5 by (2). For the CIRCUSIV test conditions $\alpha_{\mathrm{SA}}$ is at its maximum value of 0.9 , which is apparently too high. There is no churn flow regime for vertical flow models in both RELAP5 and TRACE. Thus, it is difficult for the codes to identify periodic transitions between annular and churn flow regimes in test I-2 (Figure 7) and short appearance of the annular flow regime in test I-1 (Figure 12).

4.1.3. Sensitivity Calculations for Two-Phase Flow Instability. A number of selected sensitivity calculations were carried out in order to investigate the differences between calculated amplitude of the inlet flow rates and the experiments, especially the overestimation of maximum inlet flow rate by TRACE in test I-1. It is known that the inlet water temperature is one of the most influential input parameters affecting thermal hydraulic behavior of the system. Calculations were 

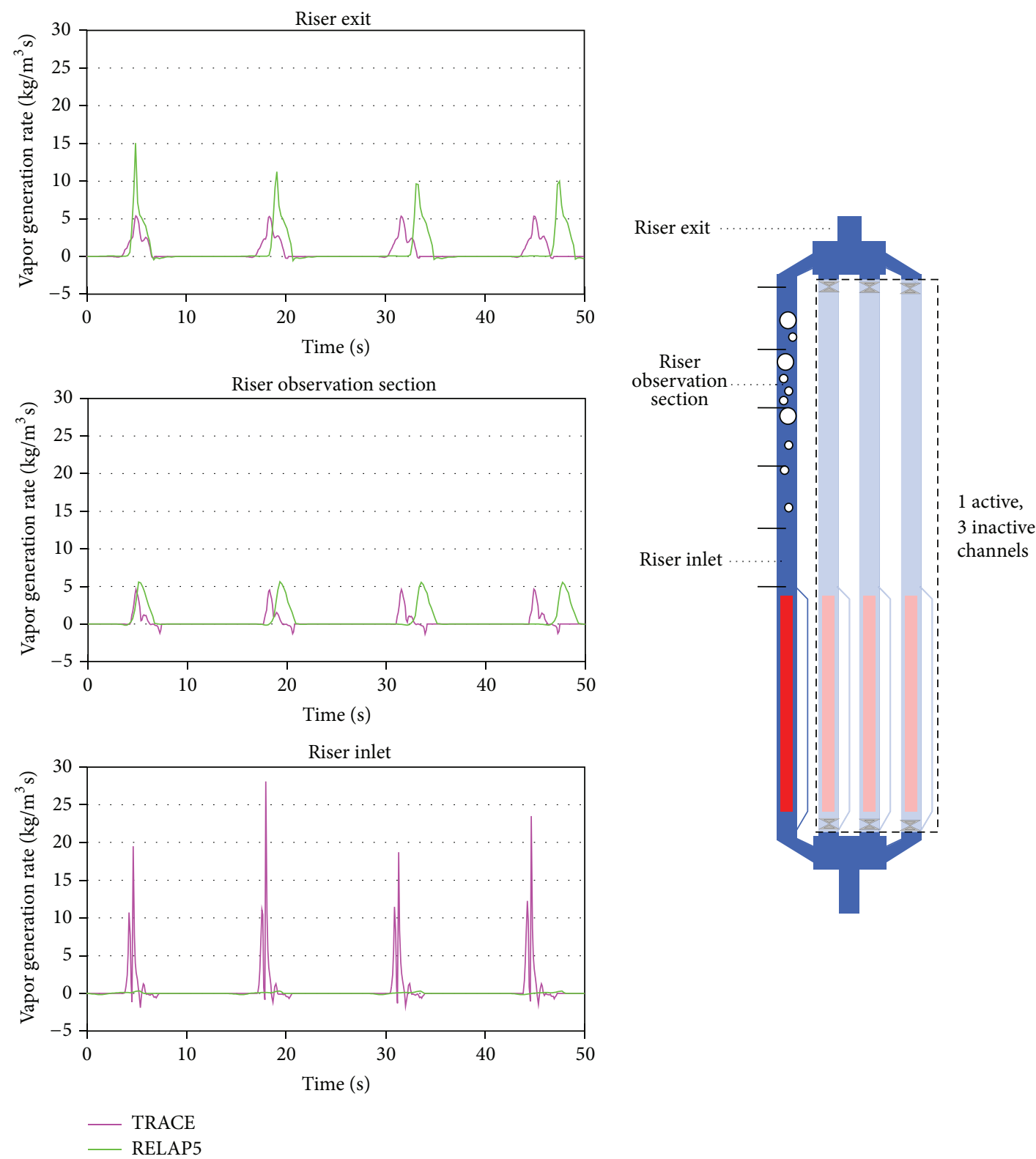

FIGURE 10: Test I-2: vapor generation rate in the riser.

carried out at inlet water temperature of $91.3^{\circ} \mathrm{C}, 94.5^{\circ} \mathrm{C}$ using TRACE and $92.6^{\circ} \mathrm{C}, 94.6^{\circ} \mathrm{C}$ using RELAP5.

Figure 13 shows maximum, average, and minimum values of the inlet flow rate obtained in the sensitivity calculations for I-1 and I-2. Figure 14 further compares the respective oscillation periods. With increase in the inlet temperature, TRACE results showed increase in the average value of inlet flow rate and decrease in the oscillation period, but no significant change in the maximum inlet flow rate was observed. RELAP5, however, provided more physically reasonable results by showing increase in all the average, maximum, and minimum values of inlet flow rate [11]. We found no explanation for this behavior in the TRACE results.

The sensitivity analysis shows that despite misidentification of the instantaneous flow regime, both codes can predict general behavior of two-phase natural circulation flow instability at atmospheric pressure.

Given the differences between experimental and predicted flow regimes, the quality of numerical solution by the STH codes is quite remarkable. In theory, STH code must identify correctly two-phase flow regime in order to select proper correlations for mass, energy, and momentum transfer. Obtained results suggest that the codes do not need to predict the flow regime correctly in order to obtain reasonably good agreement with experimental data. This can be explained if flow regime misidentification is compensated by the other models and closures.

This might have happened in the process of STH code models "tuning" for prediction of such flow characteristics as temperature, mass flow, pressure drop, and so forth without 


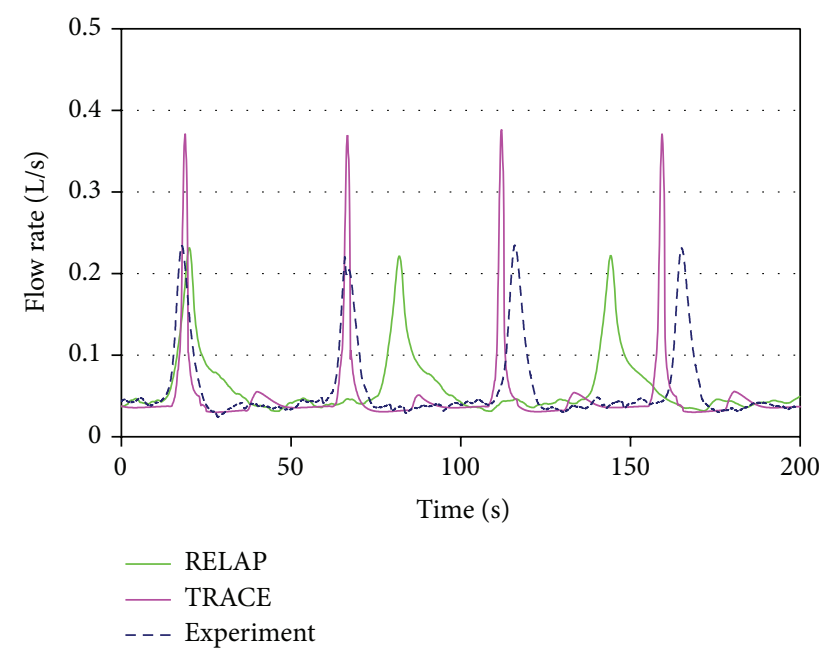

FIGURE 11: Test I-1: inlet flow rate.

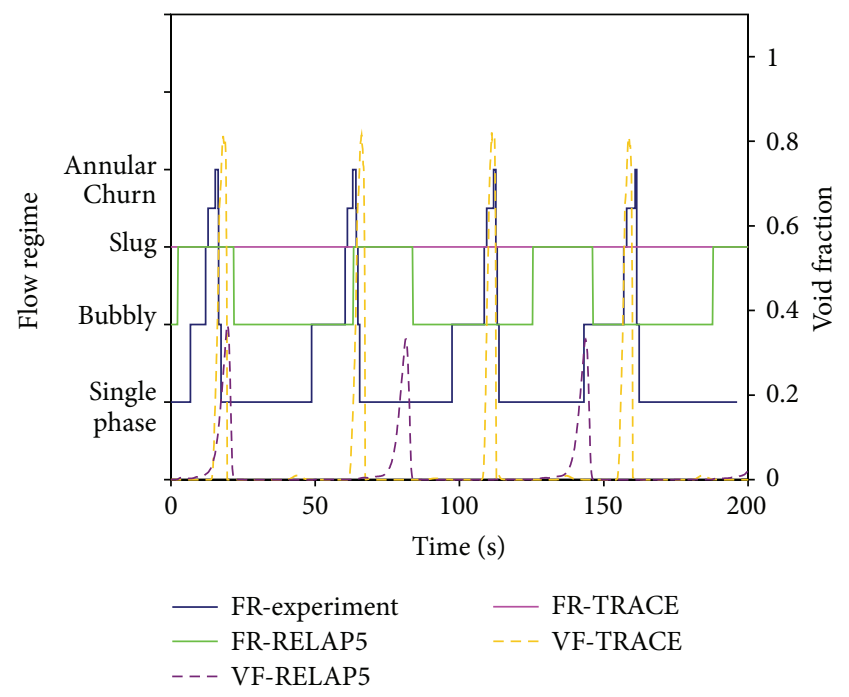

Figure 12: Test I-1: riser flow regime (FR) and void fraction (VF) in the section for visual observation.

having data on the flow regimes, which is quite often the case in large scale, high pressure, and temperature experiments. For instance, it is mentioned in the RELAP5 manual that setting of $\alpha_{\mathrm{BS}}^{*}=0.001$ in the small pipe flow regime model was "incorporated purely to obtain better agreement with experimental data." In such process of model tuning to match thermal hydraulic parameters, "flow regime" function (as a selector of most adequate closures for given flow conditions) might have become more important than its original meaning, that is, parameter that describes actual flow topology. These speculations might be verified by analysis of sensitivity of code predictions to improvements in the identification of the flow regimes.

4.2. Modification of the Flow Regime Map in RELAP5. In this section, we present results of sensitivity of thermal hydraulic parameters to variations in the flow regime transition boundaries $\alpha_{\mathrm{BS}}$ and $\alpha_{\mathrm{SA}}$ using RELAP5. As discussed in the previous section, early transition bubbly-to-slug flow regime is due to the too low value of $\alpha_{\mathrm{BS}}$, while no annular flow regime in simulation results is most likely due to the too large value of $\alpha_{\mathrm{SA}}$. Table 6 shows flow regime maps (the default and six modifications) that were used in the present sensitivity analysis. Test I-2 was selected for the analysis because higher void fraction in this test was expected to make it more sensitive to modifications of the slug-to-annular transition boundary.

Results of simulations with different $\alpha_{\mathrm{BS}}$ are presented in Table 7. The discrepancy between predicted and experimental maximum amplitude and frequency of the instability increased when $\alpha_{\mathrm{BS}}$ was increased in order to delay the transition to slug regime according to experimental observation. Decreasing $\alpha_{\mathrm{BS}}$ below the default value resulted in numerical instabilities in the code solution. Results are presented in more detail in Figures 15-18.

In Figure 15 a comparison of experimental and predicted flow regimes in the riser is provided. It is clear that predicted flow regimes became qualitatively closer to the experimental ones with $\alpha_{\mathrm{BS}}=0.25$ and $\alpha_{\mathrm{SA}}=0.55$. However, results of flow prediction with modified $\alpha_{\mathrm{BS}}$ and $\alpha_{\mathrm{SA}}$ gave worse oscillation period and inlet flow rate (Figure 16). When only $\alpha_{\mathrm{BS}}$ was increased, the maximum inlet flow rate increased and characteristic shape of the oscillation was preserved. When only $\alpha_{\mathrm{SA}}$ was decreased, the maximum inlet flow rate slightly decreased and significant distortion in the shape of oscillation appeared. Changing $\alpha_{\mathrm{BS}}$ and $\alpha_{\mathrm{SA}}$ simultaneously resulted in both increase in the maximum inlet flow rate and distortion in the shape of oscillation. When $\alpha_{\mathrm{SA}}$ was modified, strong void fraction oscillation appeared in the riser during the flashing (Figure 17). Significant changes in vapor generation rate in the riser were observed when changing the flow regime transition boundaries (Figure 18).

Obtained results suggest that thermal hydraulic parameters are sensitive to the flow regime identification by the code. However, improvement of the flow regime identification alone worsens results of RELAP5 prediction for the other thermal hydraulic parameters. This implies that modification of the steady state flow regime map in RELAP5, in order to account flow relaxation in transient phenomena, would require also corrections in respective correlations for heat, mass, and momentum exchange between the phases.

\section{Conclusions}

Presented results shed new light on the importance of the flow regime identification in STH codes. RELAP5 and TRACE codes were validated against two-phase natural circulation flow instability at atmospheric pressure. Given the default flow regime map, the codes in general predicted well flow parameters (flow rate, temperature, and pressure), except that both codes overestimated the maximum amplitude of the oscillation flow rate (up to $17 \%$ by RELAP $5,60 \%$ by TRACE).

Both codes could not identify correctly instantaneous flow regimes and regime transition timing. Small diameter 


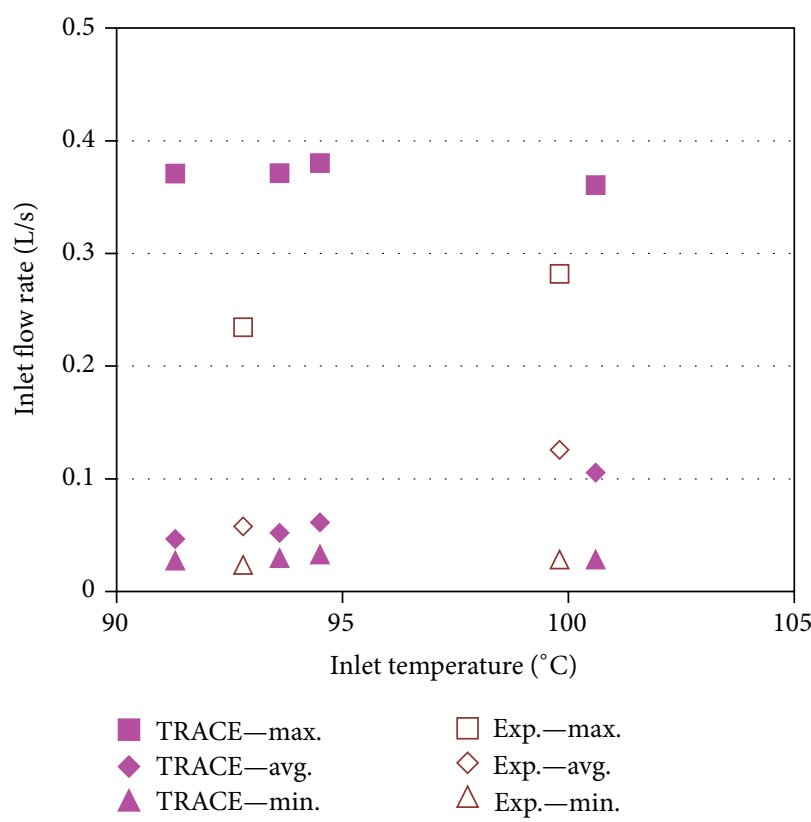

(a)

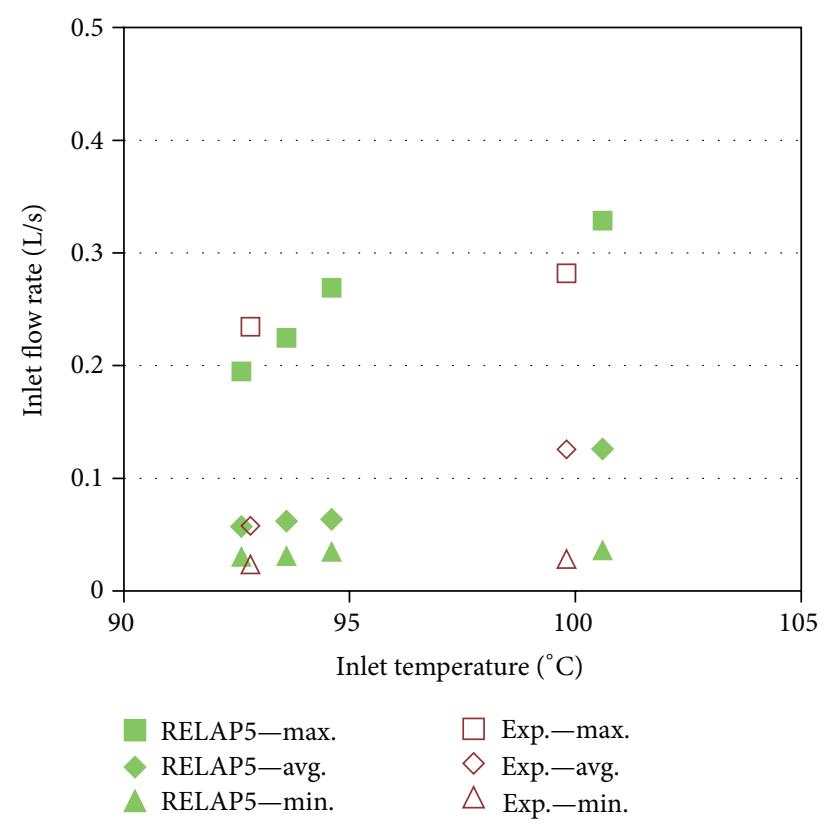

(b)

FIGURE 13: Inlet flow rate sensitivity to the inlet temperature: (a) TRACE and (b) RELAP5.

TABLE 6: Simulations with different flow regime transition boundaries.

\begin{tabular}{lcc}
\hline Simulation number & $\begin{array}{c}\text { Bubbly-to-slug } \\
\text { transition boundary } \\
\alpha_{\mathrm{BS}}^{*}\end{array}$ & $\begin{array}{c}\text { Slug-to-annular } \\
\text { transition boundary } \\
\alpha_{\mathrm{SA}}\end{array}$ \\
\hline 0 (default) & $10^{-3}$ (default) & 0.9 (default) \\
1 & 0.25 & 0.9 (default) \\
2 & 0.05 & 0.9 (default) \\
3 & $10^{-5}$ & 0.9 (default) \\
4 & $10^{-8}$ & 0.9 (default) \\
5 & $10^{-3}$ (default) & 0.55 \\
6 & 0.25 & 0.55 \\
\hline
\end{tabular}

pipe model in RELAP5 flow regime map leads to overestimation of the duration of slug flow regime. TRACE uses a combined bubbly-slug flow regime with no transition between them. Both codes failed to identify presence of the annular flow regime in the tests.

Flow regime transition boundaries in RELAP5 were modified and a better match to experimental data was obtained. However, prediction of the other thermal hydraulic parameters deteriorated. We speculate that the reason for such result is that RELAP5 and TRACE closures were tuned to predict average flow characteristics when flow regimes were not observable. In the tuning process the error in flow regime identification could have been compensated by tuning of the other closures.

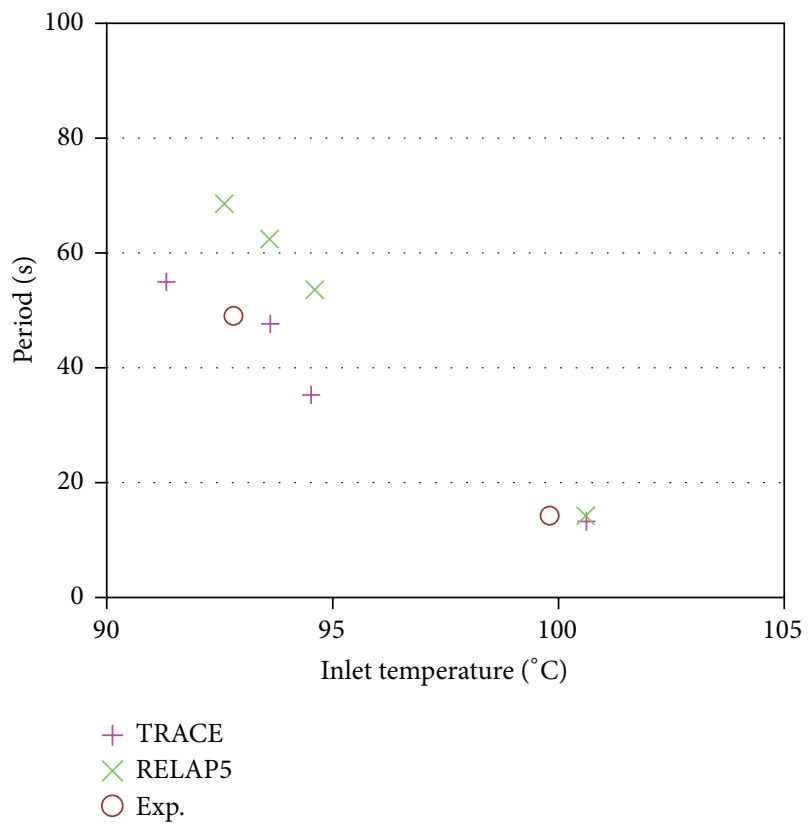

FIGURE 14: Oscillation period sensitivity to the inlet temperature.

It is instructive to note that the codes were not originally designed to calculate either flow in small pipes or dynamics of two-phase flow instability at atmospheric pressure. Therefore, the overall quality of prediction of thermal hydraulics phenomena by the codes is quite remarkable. 
TABLE 7: Inlet flow rate and oscillation period from calculations with varying bubbly-to-slug transition boundary and the experiment.

\begin{tabular}{lcccr}
\hline & & RELAP5 $\alpha_{\text {BS }}$ & & $\leq 10^{-5}$ \\
& 0.25 & 0.05 & 0.001 (default) & \\
Inlet flow rate (L/s) & & & & \\
$\quad$ Average & 0.123 & 0.123 & 0.126 & Numerically unstable \\
Max. & 0.382 & 0.359 & 0.329 & 0.126 \\
Min. & 0.032 & 0.034 & 0.036 & 0.029 \\
Oscillation period (s) & 13.2 & 13.9 & 14.2 & 14.3 \\
\hline
\end{tabular}
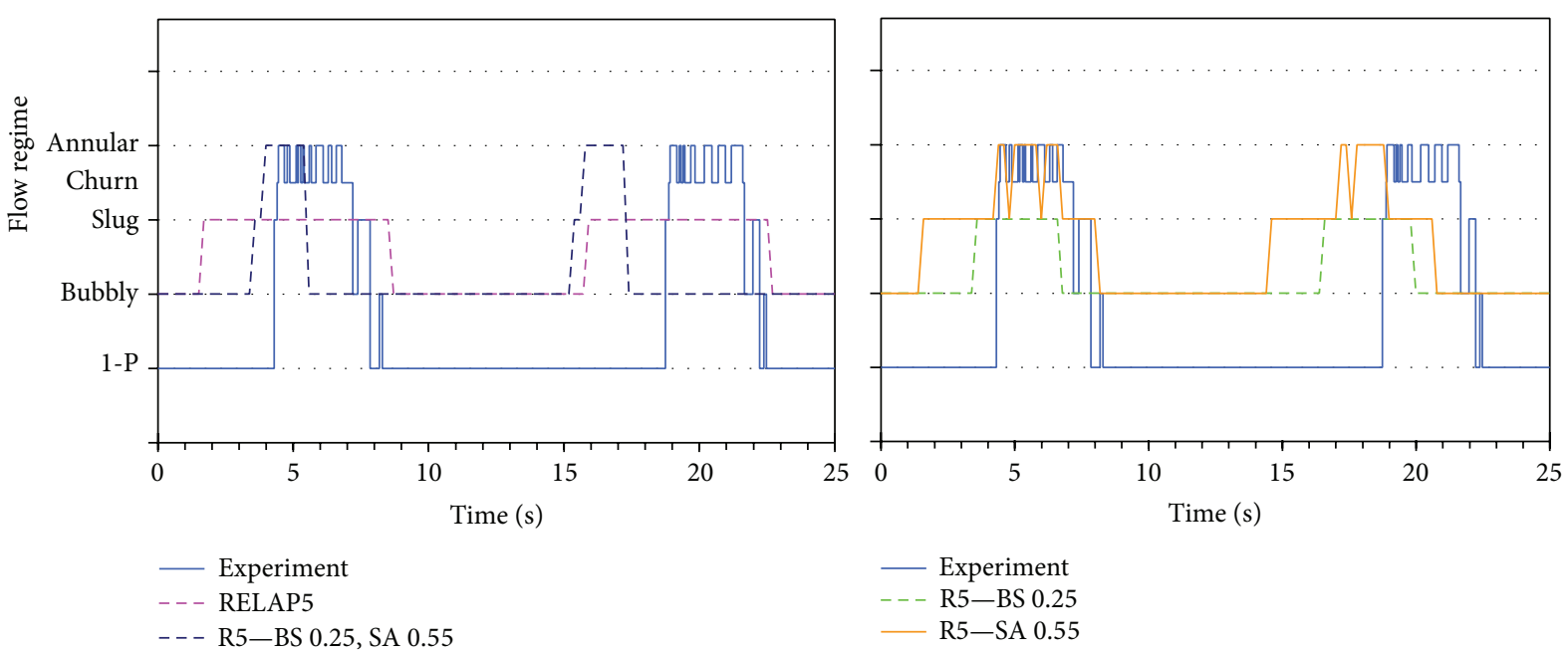

FIGURE 15: Flow regime in the riser observation section: experimental and RELAP5 data using different flow regime transition boundaries (BS: bubbly-slug; SA: slug-annular).

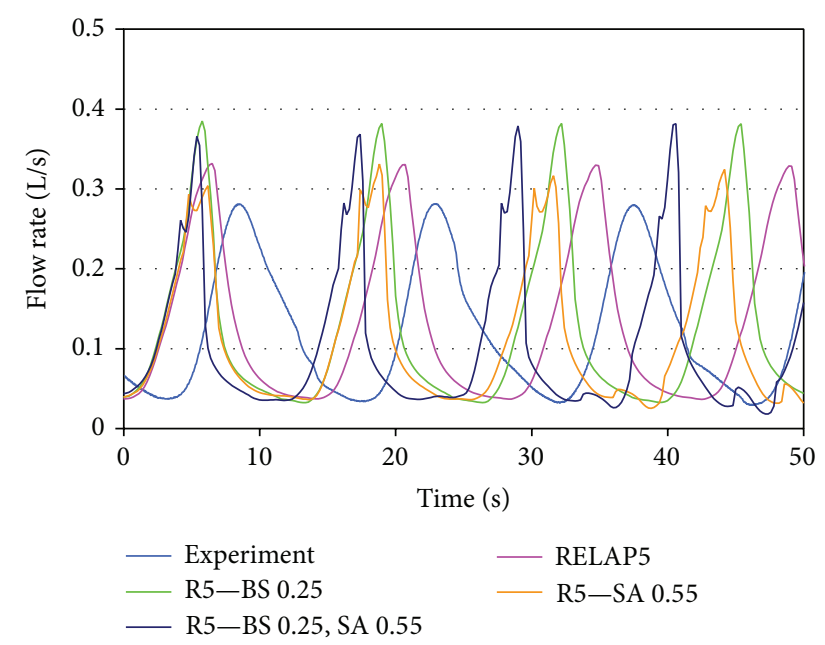

FIGURE 16: Inlet flow rate: experimental and RELAP5 data obtained with different flow regime transition boundaries.

\section{Conflict of Interests}

The authors declare that there is no conflict of interests regarding the publication of this paper.

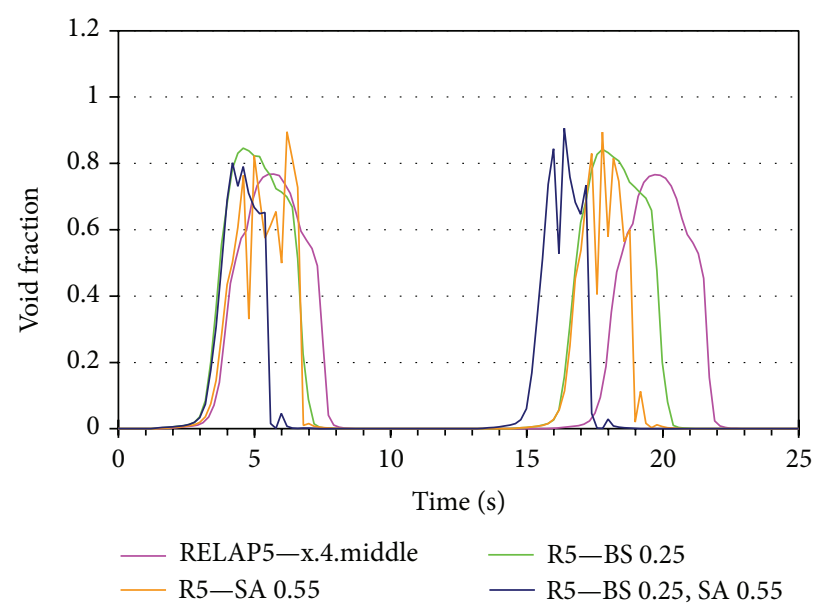

FIGURE 17: Void fraction at the riser: experimental and RELAP5 data obtained with different flow regime transition boundaries.

\section{Acknowledgments}

The authors would like to thank Dr. Martin Rohde (Delft University of Technology, The Netherlands) for discussions, 


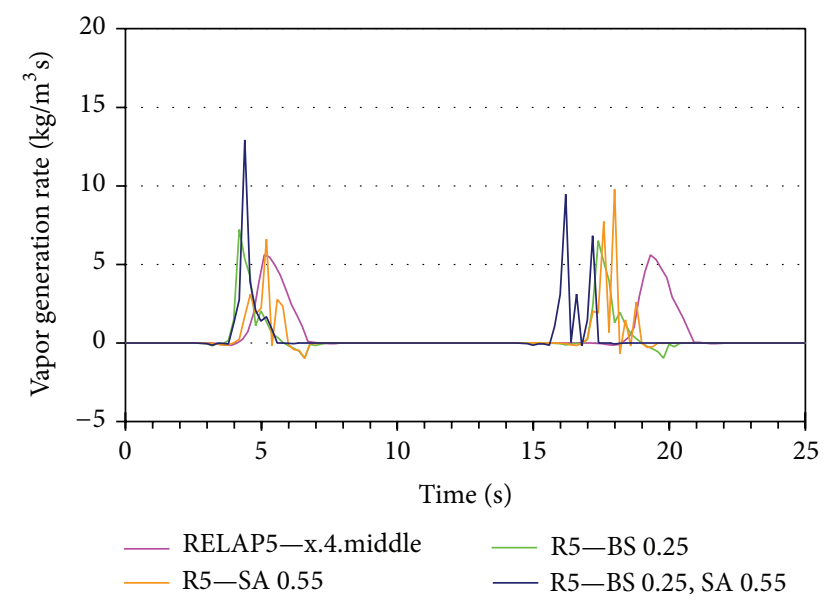

FIGURE 18: Vapor generation rate at the riser observation section predicted by RELAP 5 using different flow regime transition boundaries.

for providing the access to the CIRCUS experimental facility, and for his help in obtaining experimental data. The authors would like to thank Dr. Tomasz Kozlowski (University of Illinois, US) for his helpful consultation and support regarding RELAP5 and TRACE calculations.

\section{References}

[1] S. Z. Rouhani and M. S. Sohal, "Two-phase flow patterns: a review of research results," Progress in Nuclear Energy, vol. 11, no. 3, pp. 219-259, 1983.

[2] L. Cheng, G. Ribatski, and J. R. Thome, "Two-phase flow patterns and flow-pattern maps: fundamentals and applications," Applied Mechanics Reviews, vol. 61, no. 5, 2008.

[3] V. H. Ransom, "RELAP5/MOD2: for PWR transient analysis. s.l," in Proceedings of the International Conference on Numerical Methods in Nuclear Engineering, Montreal, Canada, September 1983.

[4] USNRC and ISL, RELAP5/MOD3.3 Code Manual, Volume IV: Models and Correlations, USNRC, ISL, Idaho Falls, Idaho, USA, 2001.

[5] USNRC, TRACE V5.0 Assessment Manual Main Report, Division of Risk Assessment and Special Projects, Office of Nuclear Regulatory Research, 2008.

[6] D. Lucas, E. Krepper, and H.-M. Prasser, "Development of cocurrent air-water flow in a vertical pipe," International Journal of Multiphase Flow, vol. 31, no. 12, pp. 1304-1328, 2005.

[7] R. T. French, "An evaluation of piping heat transfer, piping flow regimes, and steam generator heat transfer for semiscale Mod1 isothermal tests," Tech. Rep. ANCR-1229, NRC-2, Aerojet Nuclear Company, 1975.

[8] P. G. Prassinos and C. K. Liao, "Investigation of two-phase flow regimes in LOFT piping during loss-of-coolant experiments," Tech. Rep. NUREG/ CR-0606, TREE-1244, EG\&G, Idaho Falls, Idaho, USA, 1979.

[9] V.-A. Phung, P. Kudinov, D. Grishchenko, and M. Rohde, "Input calibration and validation of RELAP5 against CIRCUSIV single channel tests on natural circulation two-phase flow instability," Science and Technology of Nuclear Installations, vol. 2015, Article ID 130741, 14 pages, 2015.
[10] C. P. Marcel, M. Rohde, and T. H. J. J. van der Hagen, "Out-ofphase flashing induced instabilities in the CIRCUS facility," in Proceedings of the 11th International Topical Meeting on Nuclear Reactor Thermal-Hydraulics (NURETH '05), Avignon, France, October 2005.

[11] A. Manera and T. H. J. J. Van Der Hagen, "Stability of naturalcirculation-cooled boiling water reactors during startup: experimental results," Nuclear Technology, vol. 143, no. 1, pp. 77-88, 2003.

[12] E. H. Wissler, H. S. Isbin, and N. R. Amundson, "Oscillatory behavior of a two-phase natural-circulation loop," AIChE Journal, vol. 2, no. 2, pp. 157-162, 1956.

[13] Y. Taitel, D. Bornea, and A. E. Dukler, "Modelling flow pattern transitions for steady upward gas-liquid flow in vertical tubes," AIChE Journal, vol. 26, no. 3, pp. 345-354, 1980.

[14] O. C. Jones Jr. and N. Zuber, "The interrelation between void fraction fluctuations and flow patterns in two-phase flow," International Journal of Multiphase Flow, vol. 2, no. 3, pp. 273306, 1975.

[15] A. Petruzzi and F. D’Auria, Thermal-Hydraulic System Codes in Nulcear Reactor Safety and Qualification Procedures. Science and Technology of Nuclear Installations, 2008.

[16] L. Chen, Y. S. Tian, and T. G. Karayiannis, "The effect of tube diameter on vertical two-phase flow regimes in small tubes," International Journal of Heat and Mass Transfer, vol. 49, no. 2122, pp. 4220-4230, 2006. 


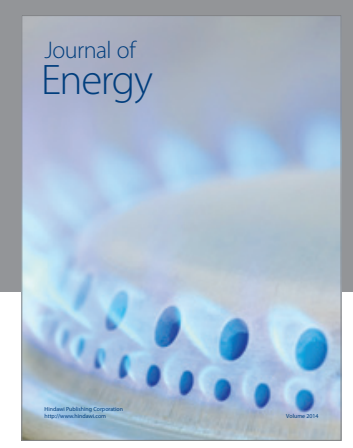

Journal of

Industrial Engineering
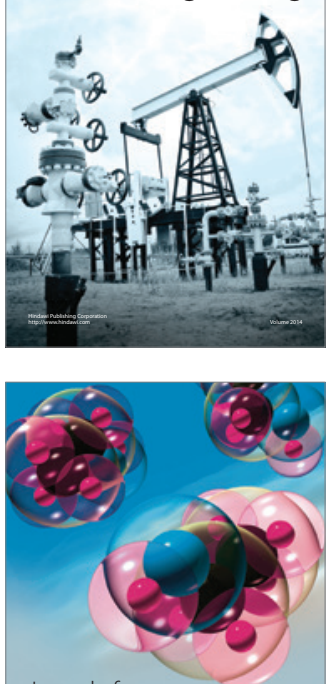

Fuels
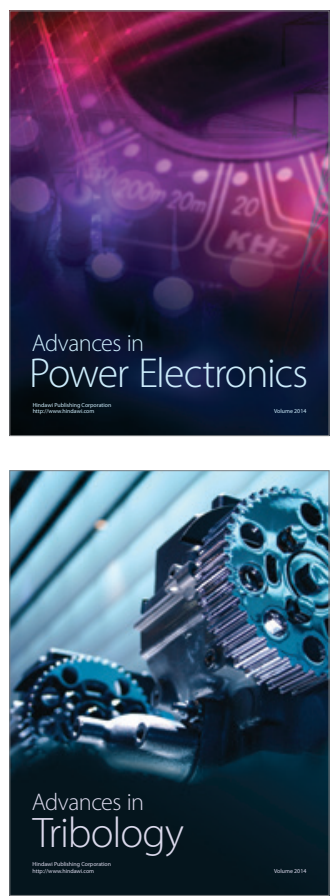

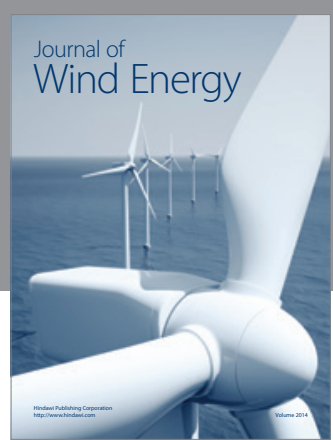

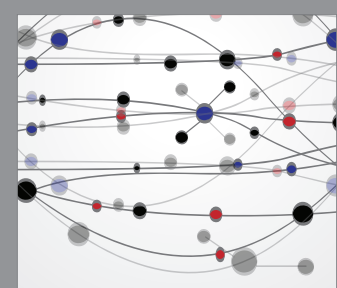

The Scientific World Journal

Submit your manuscripts at http://www.hindawi.com

Journal of

Structures
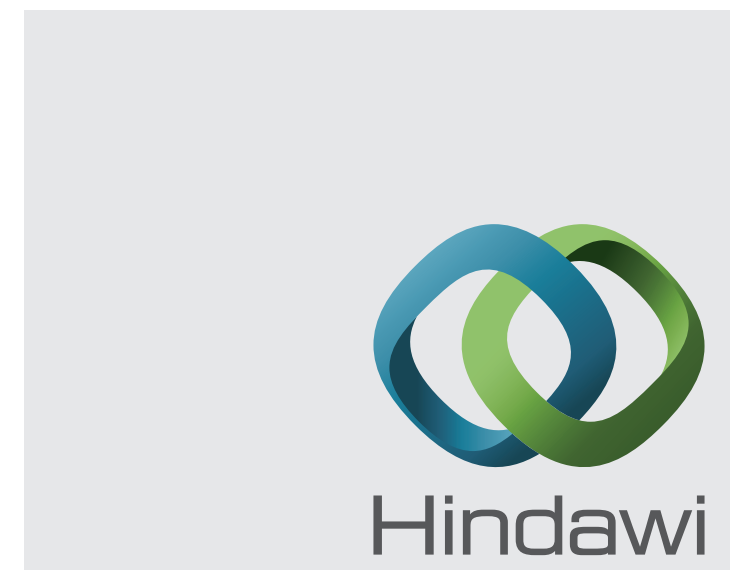

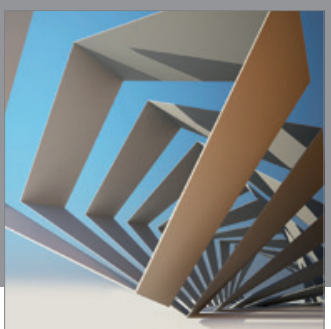

Rotating

Machinery
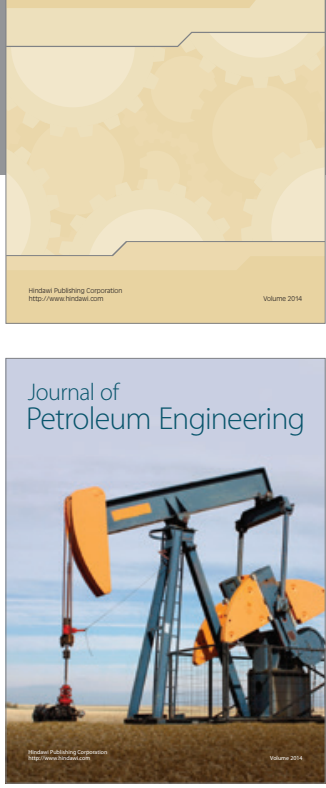

Journal of

Solar Energy
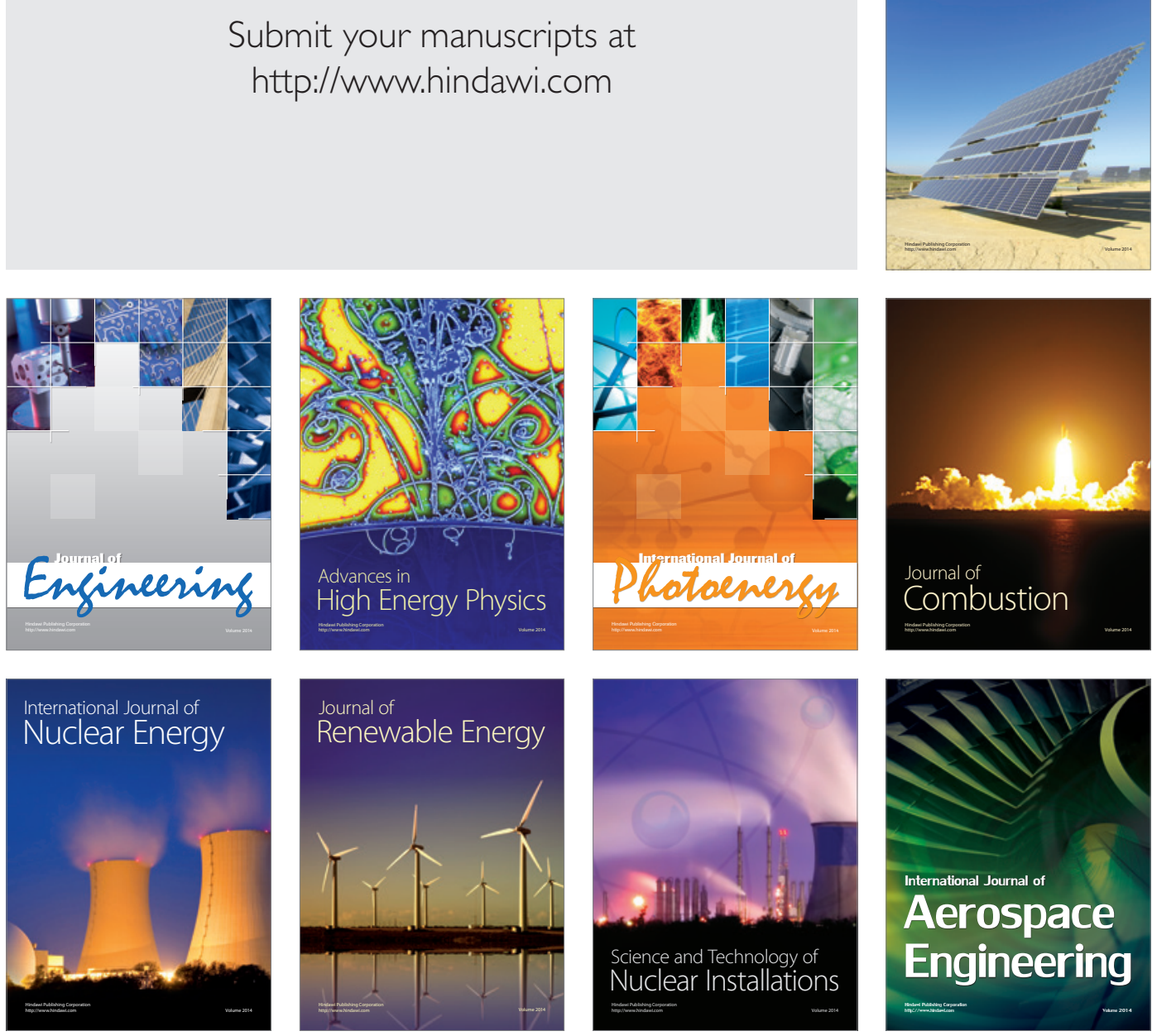